CALEI-

DOSCOPIO

35 / 36

खु

JULIO - DICIEMBRE 2016 ENERO - JUNIO 2017

\section{Explotación del territorio y resistencia campesina. El caso de los pueblos de Santiago y San Pedro Ocuila en Cuencamé, Durango}

\title{
RESUMEN
}

En la transición del siglo XIX al xx, el estado de Durango, al igual que el resto del norte del país, se encontraba inmerso en un proceso de reestructuración política y económica a causa de su condición de productor de materias primas, que lo colocaba en una estrecha relación con los mercados europeo y estadounidense. El Partido de Cuencamé (actuales municipios de Cuencamé, Peñón Blanco y Santa Clara) constituyó el ejemplo más representativo en la entidad de las contradicciones de dicho proceso.

Además, se destacan los casos de los Pueblos Unidos de Santiago y San Pedro de Ocuila, como uno de los principales antecedentes de la Revolución mexicana en el oriente de Durango, ya que, a través de una lucha legal y finalmente militar, lograron hacer frente al expansionismo de los latifundios de la región. Esto generó una redefinición de las relaciones sociales a partir de dicha resistencia.

Palabras clave: explotación, interconectividad, latifundios, conflictos, comunidades.

1 Alumno de la maestría en Ciencias y Humanidades con terminación en Historia, Universidad Juárez del Estado de Durango. 
In the transition from the nineteenth and twentieth centuries the State of Durango, like the rest of the north of the country was immersed in a process of political and economic restructuring, because of its status as a producer of raw materials, placing him in close relationship with European and American markets. Since the Party Cuencamé (present municipalities of Cuencamé, Peñón Blanco and Santa Clara), was the most representative example in the state, of the contradictions of this process.

They excel in that territory if the United Peoples of Santiago and San Pedro de Ocuila, as one of the main background of the Mexican Revolution in eastern Durango, as through a legal and finally military struggle, managed to cope with the expansionism of large estates in the region. This generated a redefinition of social relations from this resistance.

Keywords: exploitation, interconnectivity, Great Hacienda, conflicts, communities

\section{INTRODUCCIÓN}

\section{$\mathrm{E}_{1}$} presente trabajo aporta a la reflexión sobre las relaciones entre las estructuras sociales y los conflictos armados, ya que los sucesos de los pueblos de Santiago y San Pedro Ocuila marcaron un antes y un después en la región de Cuencamé. Posteriormente al intento de levantamiento ocurrido en dicho territorio, las relaciones sociales de las pequeñas comunidades con las estructuras de las haciendas, las autoridades políticas y, en última instancia, la dinámica interna, no volverían a ser las mismas. Gracias a la diferenciación que hacían de sí mismos a partir de la lucha constante con los "otros" que buscaban apoderarse de sus tierras, pudieron incrustarse en una dinámica nacional, pues generaron nuevos lazos de identidad y de interrelación de intereses con elementos más amplios de la vida mexicana. 


\section{DIVISIÓN DEL ESTADO DE DURANGO}

El norte del territorio mexicano había permanecido aislado del control de las autoridades nacionales durante la mayor parte del siglo XIX. ${ }^{2}$ Por ello, se crearon verdaderos cacicazgos regionales que imponían su voluntad por encima de las disposiciones de las autoridades oficiales; por ejemplo, la modificación de las fronteras políticas para hacerlas coincidir con sus propios intereses. ${ }^{3}$ Esta realidad se modificó paulatinamente con la consolidación del gobierno del general Porfirio Díaz, el cual se caracterizó por imponer su control sobre dichos poderes locales. ${ }^{4}$

En el estado de Durango, la Ley de División Territorial de 1905 estableció un mayor control de las autoridades sobre el territorio, por lo menos de forma oficial frente al capital extranjero y nacional, y a las poblaciones que habitaban el estado. La ley establecía, como se muestra en el siguiente mapa, que el territorio de Durango se dividiría en partidos, municipalidades y jefaturas de manzana. Así, se establecieron 13 partidos: Durango, Cuencamé, Indé, Mapimí, Mezquital, Nazas, Nombre de Dios, El Oro, San Dimas, San Juan de Guadalupe, San Juan del Río, Santiago Papasquiaro y Tamazula. Los límites que dicha ley le otorgaba al Partido de Cuencamé estaban plenamente identificados, estableciendo que al norte colindaría con los partidos de Nazas y Mapimí; al noroeste con el estado de Coahuila; al este con los partidos de San Juan de Guadalupe, Nombre de Dios y el estado de Zacatecas; y al oeste con los partidos de San Juan del Río y Durango. En cuanto a su división interna, se encontraba constituido por tres municipalidades: Cuencamé, Peñón Blanco y Santa Clara. ${ }^{5}$ A pesar de esta división, los conflictos fronterizos del Partido de Cuencamé siguieron existiendo con los estados vecinos de Zacatecas y Coahuila, lo que impidió hablar de límites totalmente concretos y definidos. ${ }^{6}$

2 Katz, Friedrich, Pancho Villa, México, Era, 1998, pp. 25-77.

3 Salmerón, Pedro, Juárez, la rebelión interminable, México, Planeta, 2007, pp. 151-152.

4 Carta de Juan Manuel Flores a Porfirio Díaz. Durango, Dgo., 22 de enero de 1891. Archivo Porfirio Díaz de la Universidad Iberoamericana (en adelante APD). Legajo: XV. Documento: 014220.

5 "Ley de División Territorial", Periódico Oficial del Gobierno del Estado de Durango, Durango, 21 de diciembre de 1905, p. 27.

6 Carta de Eduardo Contreras a Porfirio Díaz. México, D.F., 25 de marzo de 1911. APD. Legajo: XXXVI. Documento: 005187. 


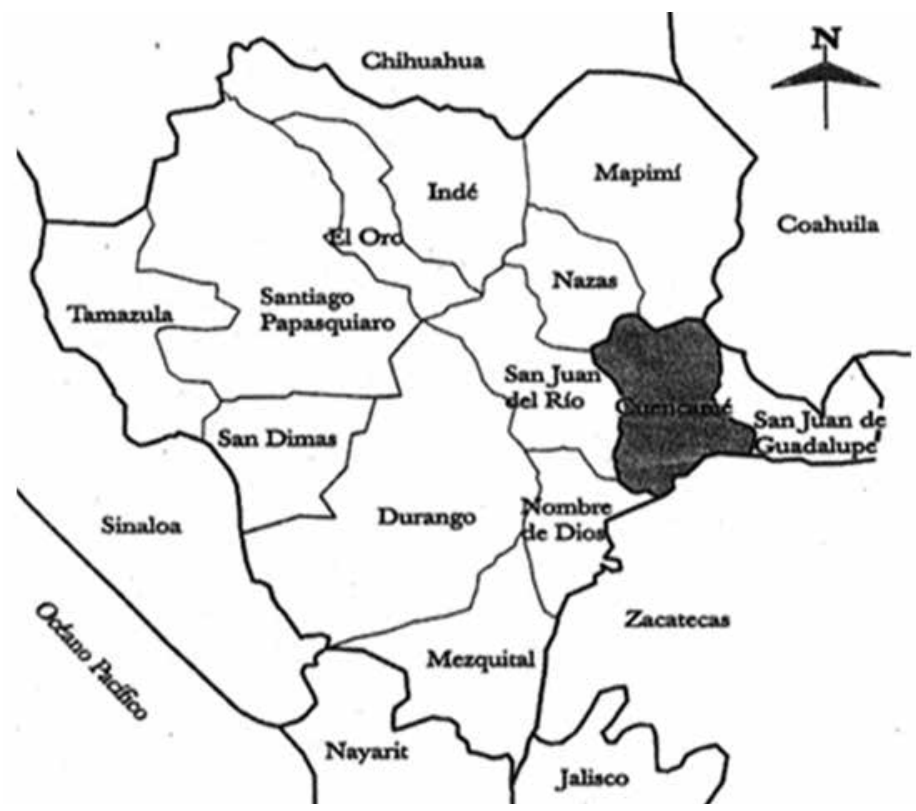

Figura 1. División política del estado de Durango, 1905. Fuente: Villa Guerrero, Guadalupe, Élites y revolución en Durango, México, Instituto de Investigación Dr. José María Luis Mora, 2010, p. 209.

\section{Geografía del Partido de Cuencamé}

El Partido de Cuencamé, como se interpreta en el siguiente mapa, se encontraba dentro de un territorio árido y semiárido, justo en la frontera entre la región de los valles y el desierto. Sus tres municipalidades presentaron características bien definidas de estas dos regiones, debido a que existieron pocas tierras cultivables por la falta de lluvia y abundantes ojos de agua y ríos que permitieron la producción ganadera. En la municipalidad de Cuencamé destacó la llanura de la Purísima y la Estanzuela, ya que se encontraba ahí la corriente fluvial más importante del Partido: el Arroyo de Cuencamé. ${ }^{7}$

7 Rouaix, Pastor, Geografía del Estado de Durango, México, Secretaría de Agricultura y Fomento, 1929, pp. 151-158. 
En cuanto a la municipalidad de Santa Clara, su territorio formó un plano de declive desde las serranías de El Temazcal y la altiplanicie de la Estanzuela hasta el cauce del río Aguanaval, territorio que fue atravesado por el río de Santa Clara y el arroyo del Saucito. ${ }^{8}$ La municipalidad de Peñón Blanco se extendió entre las sierras de Gamón y Yerbanís, las cuales constituyeron la frontera entre la región de los valles y la región semiárida; por tal motivo, los territorios de la municipalidad presentaron características de estas dos regiones, destacando, al norte de Yerbanís, el Cerro Blanco como uno de los lugares más altos del Partido y, al centro, el río Covadonga o del Álamo, cuyas aguas nacían de la vecina municipalidad de Cuencamé, en el arroyo de Peñuelas. ${ }^{9}$

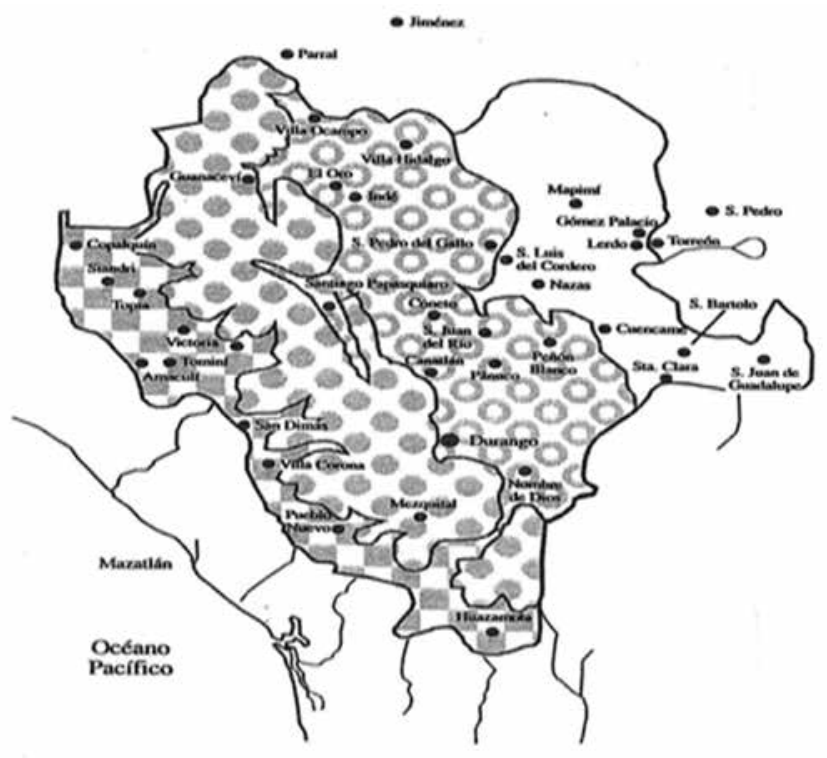

E] Zona de las Quebradas

Zona de las Cumbres de la Sierra

O] Zona de los Valles

$\square$ Zona Semiárida

Figura 2. Zonas climáticas del estado de Durango. Fuente: Martínez Guzmán, Gabino y Juan Ángel Chávez Ramírez, Durango: un volcán en erupción, México, Fondo de Cultura Económica, 1998, p. 329.

8 I6id., pp. 158-161.

9 Ibid., pp. 134-138.

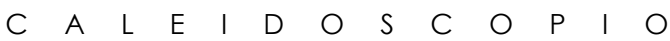


El Partido de Cuencamé experimentó un incremento poblacional considerable durante la segunda mitad del siglo XIX: de los 15,198 habitantes que tenía en 1871, pasó a 28,670 personas en 1900, y a 41,199 una década después. ${ }^{10}$ Dicho aumento de la población se debió a un mejoramiento de los sistemas de salud y de transporte, que facilitaron la movilidad de una variada población en busca de las fuentes de trabajo que garantizaran su subsistencia.

Al iniciar el siglo xx, la población del Partido se encontraba dividida de la siguiente manera:

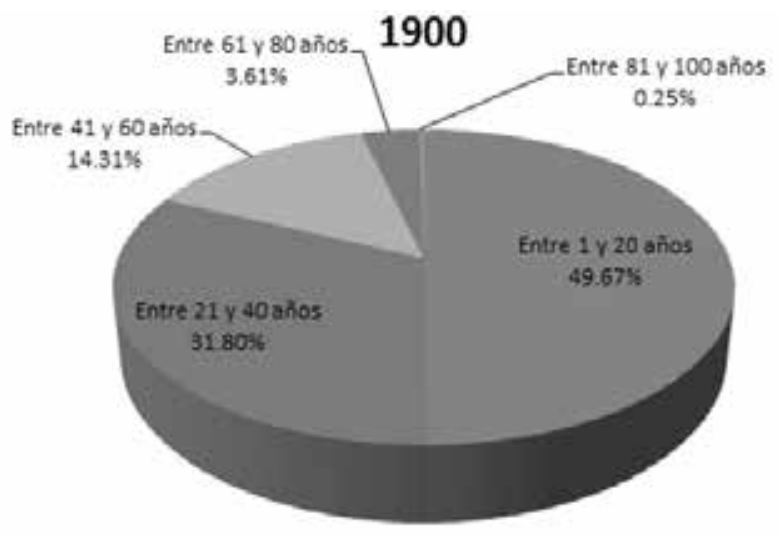

Figura 3. Distribución de la población por edades del Partido de Cuencamé, 1900. Fuente: elaboración de Daniel Guillermo Rodríguez Barragán a partir del Censo de 1900. Archivo Histórico del Estado de Durango (en adelante: AHED). Fondo: Registro civil. Caja sin clasificar.

El hecho de que gran parte de la población de Cuencamé fuera tan joven durante el proceso de recrudecimiento de los conflictos agrarios en los últimos años del siglo XIX y los primeros del XX, se convirtió en un factor que incrementó la presión de la dinámica campesina, ya que se había perdido la seguridad de la posesión de la tierra por el proceso de expansión de los latifundios.

10 Censos de 1871, 1900 y 1910. AHED. Fondo: Registro Civil. Caja sin clasificar. 
La división por oficios también puede darnos una perspectiva de la estructura social en Cuencamé, gracias a que presentaba peculiaridades que la hacían distinguirse del resto del estado. De 1895 a 1900, se presentó una tasa de crecimiento de $0.83 \%$ en las personas que declararon tener una ocupación agropecuaria y de $10.94 \%$ para los que tenían ocupación minera; mientras que para el periodo 1900-1910, la tasa fue de $5.18 \%$ para el primer caso y $5.12 \%$ para el segundo. ${ }^{11}$ Esto hace inferir que la ocupación de la tierra por parte de las haciendas y las minas no significó la pérdida absoluta de empleo para la población, sino que redefinió su relación con la tierra al seguir trabajándola, pero sin poseerla.

Se destaca que el Partido de Cuencamé tuvo 51 centros ganaderos; es decir, el mayor número en la entidad, ya que los partidos que lo siguieron fueron San Juan del Río con 20 y San Juan de Guadalupe con $11{ }^{12}$ Lo anterior demuestra la transformación que la apropiación por parte de los grandes hacendados de las tierras de las comunidades generó en la estructura social. Por tal razón, al ser poca la tierra de riego que poseían las comunidades y las haciendas, fue necesario enfocarse a la riqueza ganadera.

\section{CONECTIVIDAD FERROCARRILERA}

A principios del siglo xx, la parte oriental del estado de Durango se consolidó por el inicio de un proceso de conectividad con el resto del territorio nacional y con los intereses de los mercados internacionales. Con la llegada del Ferrocarril Internacional Mexicano en 1892 , que conectaba la ciudad de Durango con Torreón, ${ }^{13}$ se estableció una infraestructura de líneas con 16 estaciones que atravesaban todo el territorio entre la capital estatal y la Comarca Lagunera. ${ }^{14}$ Los nuevos tramos ferroviarios, más que asegurar una viable movilidad de pa-

11 Fernández de Castro, Patricia, "El Porfiriato visto a través de los censos de población", en Rodríguez López, Guadalupe (coord.), Historia General del Estado de Durango, tomo III, Siglo XIX, Durango, Instituto de Investigaciones Históricas de la Universidad Juárez del Estado de Durango, 2013, pp. 547-593.

12 Censo de 1910. AHED. Fondo: Registro Civil. Caja sin clasificar.

13 Arreola Valenzuela, Antonio, Durango, más de un siglo sobre rieles, Durango, Instituto de Investigaciones Históricas de la Universidad Juárez del Estado de Durango, 1992, p. 51.

14 "Itinerario del Ferrocarril Internacional Mexicano", Periódico Oficial del Gobierno del Estado de Durango, México, Durango, 16 de noviembre de 1902, p. 5. 
sajeros, estuvieron diseñados, en su distribución, para garantizar el trasporte de las materias primas, tanto al centro del país como a los Estados Unidos y a Europa. Cabe señalar que los ramales se convirtieron en los elementos más importantes para garantizar relaciones sólidas con los mercados internacionales, al ser los encargados de alimentar a la industria de otros países con las materias primas del norte de México. ${ }^{15}$

La llegada del ferrocarril significó la formación de dos estructuras: la meramente física y tecnológica (infraestructura) y la social (compañías ferrocarrileras y sus representantes). Estas estructuras modificaron la dinámica ya existente, especialmente a los grupos de poder (latifundistas), los cuales tuvieron que establecer una nueva relación con las autoridades federales. Gracias a que el tendido de las líneas férreas incrementó el control del régimen porfirista en los diversos territorios de México, las compañías ferrocarrileras contaron con el respaldo absoluto del gobierno nacional. ${ }^{16}$ Por ello, dichas empresas pudieron contar con una posición fuerte para ser reconocidas por los poderes locales, ya que no fueron combatidas por los terratenientes, sino que establecieron una relación marcada por la mutua dependencia y complicidad..$^{17}$ Esto facilitó que las empresas ferrocarrileras contaran con el respaldo suficiente para recibir las concesiones necesarias para sus planes de expansión. ${ }^{18}$

Sin embargo, los más afectados por esta esta relación entre gobierno y compañías ferrocarrileras fueron los campesinos que se vieron afectados por la invasión de sus tierras, pues dichas compañías contaban con el auxilio de las autoridades tanto nacionales, que presionaban para que se cumplieran las exigencias de las compañías ferrocarrileras referente a la seguridad legal sobre las tierras que necesitaban para construir el tramo entre Torreón y Durango, ${ }^{19}$ como estatales, que no dudaban en enviar a sus fuerzas rurales para reprimir

15 Arreola, op. cit., p. 59.

16 Carta de Manuel Fernández Leal a Juan Manuel Flores, México, D.F. 12 de noviembre de 1888. AHED. Fondo: Correspondencia de Gobernadores. Exp. 111.

17 Carta de Lorenzo M. Johnson a Juan Manuel Flores, Cd. Porfirio Díaz. Coah. 19 de julio de 1892. AHED. Fondo: Correspondencia de Gobernadores. Exp. 148.

18 Carta de Lorenzo M. Johnson a Gral. Juan Manuel Flores, Cd. Porfirio Díaz. Coah. 26 de julio de 1892. AHED. Fondo: Correspondencia de Gobernadores. Exp. 158.

19 Carta de Porfirio Díaz a Juan Manuel Flores, México. D.F. 9 de junio de 1891. AHED. Fondo: Correspondencia de Porfirio Díaz. Exp. 77. 
a los campesinos que agredían a los trabajadores ferrocarrileros.$^{20} \mathrm{Es}$ importante mencionar que, incluso, se presentó la donación de tierras por parte de algunos hacendados para la construcción del ferrocarril. ${ }^{21}$

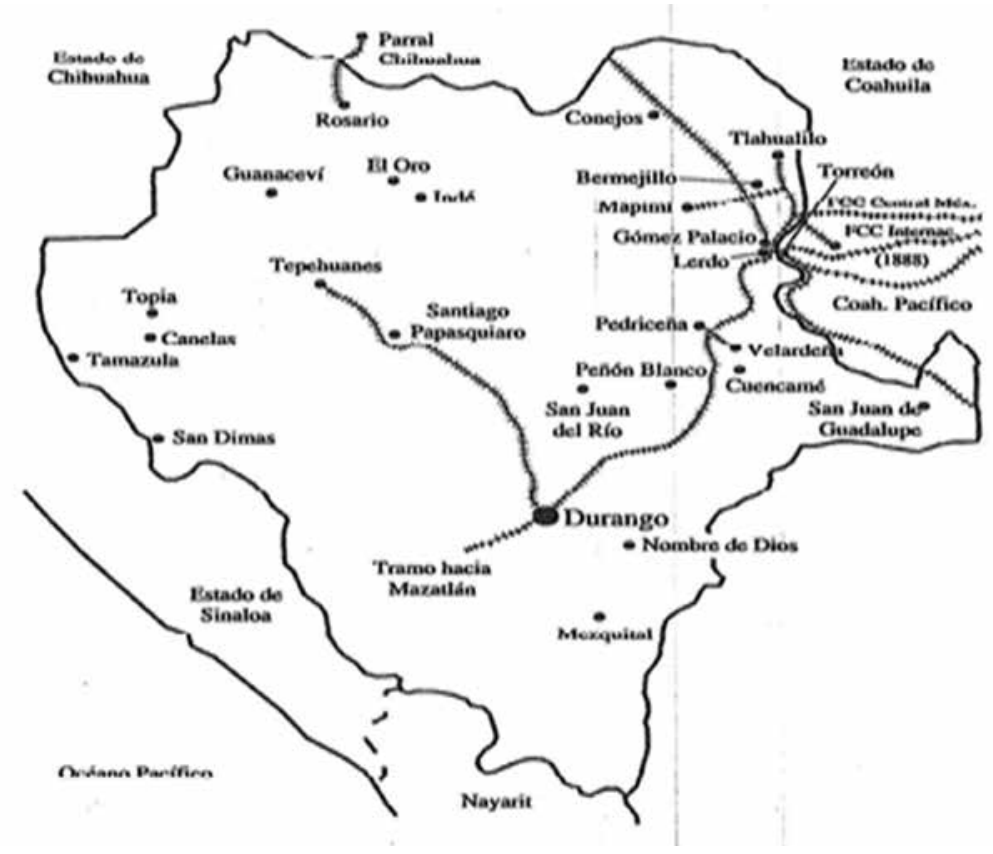

Figura 4. Plano del Ferrocarril Internacional Mexicano. Fuente: Martínez y Chávez, Durango: un volcán en .... p. 328

ACAPARAMIENTO DE LA TIERRA

Frente a este escenario, el Partido de Cuencamé presentaba características que lo hacían distinguirse del resto de la entidad, ya que regis-

20 Carta de Lorenzo M. Johnson a Juan Manuel Flores, Cd. Porfirio Díaz. Coah. 15 de mayo de 1893. AHED. Fondo: Correspondencia de Gobernadores. Exp. 48.

21 Carta de Manuel Ugarte a Porfirio Díaz. Cuencamé, Dgo. 10 de febrero de 1891. APD. Legajo: XVI. Documento: 011721. 
traba la mayor concentración de la propiedad raíz de todo Durango, ${ }^{22}$ debido a que para 1898 los latifundios (propiedades de 50,000 hectáreas o más $)^{23}$ acumulaban alrededor de $84.8 \%$ de la superficie del Partido, cantidad que se incrementaba a $97.6 \%$ si sumamos la tierra acaparada por las haciendas (propiedades de entre 10,000 y 50,000 hectáreas) ${ }^{24}$ Para 1906, las principales haciendas del partido presentaban extensiones descomunales: la hacienda de Juan Pérez, perteneciente a la familia Moncada, ocupaba 280,500 ha; la hacienda de Sombreretillos, de los López Negrete, acumulaba 83,700 ha; la hacienda de Santa Catalina del Álamo, de los Martínez del Río, tenía 418,193 ha; y la hacienda de Atotonilco, de los González Saravia, registraba 44,401 ha. ${ }^{25}$

Los latifundios y haciendas del Partido de Cuencamé tenían una importante presencia de ganado vacuno y caballar (del primero acaparaban aproximadamente 7,000 cabezas de las 10,000 registradas, y del segundo 11,000 de las 12,000 cabezas empadronadas). En el ganado asnal (tan importante en el trabajo del campo), el partido muestra un acaparamiento similar, ya que los latifundios poseían 900 cabezas y las haciendas 450, de los 1,500 burros registrados aproximadamente. Pero el acaparamiento más contundente se daba en el ganado menor (borregos y caprinos), ya que de las casi 250,000 cabezas en el partido, las haciendas tenían aproximadamente 60,000 y los latifundios 180,000 , lo cual coincide con su abundancia de tierra de agostadero. ${ }^{26}$

Las comunidades campesinas, al iniciar el siglo xx, quedaron rodeadas por los enormes latifundios: la comunidad de Sauces de Salinas quedó en los bordes que separaban las haciendas de Santa Catalina y Juan Pérez; Peñón Blanco estuvo totalmente rodeado por la hacienda de Santa Catalina; Cuencamé se encontró entre las ha-

22 Salmerón, Pedro, La División del Norte: la tierra, los hombres y la historia de un ejército del pueblo, México, Planeta, 2006, p. 155.

23 La clasificación de latifundios y haciendas según su extensión es propuesta por Pastor Rouaix y retomada por Cano Cooley, Gloria, "Tenencia de la tierra en el Estado de Durango según los padrones catastrales de 1898", Tesis de maestría, Instituto de Investigaciones Históricas de la Universidad Juárez del Estado de Durango, 2013.

24 Ibid., p. 95.

25 Memoria presentada al $\mathrm{H}$. Congreso del Estado por el gobierno del mismo, sobre los actos de administración pública durante el periodo del 16 de septiembre de 1904 al 16 de septiembre de 1906, Durango, Imprenta de la Mariposa, 1906, Anexo 48. AHED. Fondo: Secretaría de Gobierno siglo XX.

26 Cano Cooley, op. cit., pp. 126-130. 
ciendas de Santa Catalina y Sombreretillos; y Santiago y San Pedro Ocuila se ubicaron entre las haciendas de Sombreretillos y Atotonilco. Lo cual generó que la mitad de los habitantes de los municipios de Cuencamé y Peñón Blanco tuvieran que residir dentro del territorio de las haciendas y el resto se distribuyera entre los centros mineros y dichas comunidades campesinas. ${ }^{27}$

\section{ESTRUCTURA MINERA}

Cuencamé se diferenciaba también por tener una de las producciones mineras más importantes del estado. La compañía ASARCo reactivó el mineral de Velardeña a finales del siglo xIX por la estabilidad política y la seguridad en los caminos propiciada por el régimen porfirista. ${ }^{28} \mathrm{La}$ ASARCO, fundada en 1899, y que vivió sus mejores años de expansión en Cuencamé entre 1903 y 1905, ${ }^{29}$ es el principal ejemplo de cómo la minería modificó radicalmente la estructura de la sociedad en Cuencamé, debido a que estableció una interrelación entre los centros productores agrícolas con los núcleos mineros, los cuales, al mismo tiempo que representaban un mercado cercano de consumidores, que en gran medida determinaban la producción de haciendas y comunidades campesinas, también se convirtieron en una alternativa laboral a las estructuras de los latifundios. Lo anterior explica el incremento poblacional de Velardeña, que de 3,138 habitantes que presentaba en 1900, había aumentado a 5,939 una década después. ${ }^{30}$ Para 1910, en el Partido de Cuencamé había registrados únicamente 1,420 mineros, muy por

27 Walker, David, "Continuidad y cambio en Cuencamé, Durango 1895-1930", Ponencia presentada en el Congreso Anual del Departamento de Estudios Latinoamericanos de las Rocallosas, Colorado, 18-20 de febrero de 1999, documento sin publicar en resguardo del Instituto de Investigaciones Históricas de la Universidad Juárez del Estado de Durango. Agradezco a la Mtra. María Guadalupe Rodríguez López, investigadora de dicho instituto, el haberme proporcionado esta información.

28 Villa Guerrero, Guadalupe, "La minería en la era de la paz y del trabajo", en Cano Cooley, Gloria y Mario Cerutti (coords.), Porfiriato y revolución en Durango, Durango, Instituto de Investigaciones Históricas de la Universidad Juárez del Estado de Durango, 1992, pp. 81-127.

29 Villa Guerrero, Guadalupe, "Durango en la era de la paz y del progreso", en Altamirano, Graziella et al. (coords.), Durango, una historia compartida 1821-1920, México, Instituto de Investigación Dr. José María Luis Mora, 1997, pp. 234-350.

30 Censos de 1900 y 1910. AHED. Fondo: Registro Civil. Caja sin clasificar.

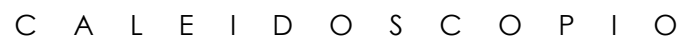


encima de sus vecinos, ya que San Juan del Río presentaba 739 y San Juan de Guadalupe sólo 344.31

Por lo anterior, se encuentra una población con múltiples perspectivas de sobrevivir a los embates de las haciendas, debido a que la minería ofrecía una salida laboral a las familias campesinas despojadas de sus tierras y que no querían o no podían trabajar en los latifundios. Como muestra, el número de habitantes de Velardeña era superior al número de mineros registrados, ya que alrededor de las minas no todos se dedicaban exclusivamente a la extracción de metales. Esto generó una pluralidad de oficios: comerciantes, vaqueros encargados del ganado, obreros dedicados al mantenimiento de la maquinaria, entre otros.

Además, la minería se convirtió en una alternativa laboral atractiva frente a las estructuras de los latifundios, ya que si tomamos en cuenta que, en promedio, en las haciendas de la región los salarios que variaban entre 1.12 y 4 pesos diarios se pagaban de manera mensual con constantes retrasos; ${ }^{32}$ en la minería el sueldo para los peones podía oscilar entre 1.50 y 3 pesos, pero siempre se pagaba de forma diaria y, en algunos casos, sin la presencia de la tienda de raya. ${ }^{33}$

De hecho, los terratenientes hicieron campañas de ocupación de las tierras que eran de los campesinos, ya que algunos centros mineros se desarrollaron por el de explotación de los recursos naturales. Asimismo, las compañías mineras participaron en el proceso de acaparamiento de tierras en alianza con los terratenientes. ${ }^{34}$

El proceso de explotación minera muestra profundas contradicciones, ya que mientras incrementaba la presión sobre los grupos campesinos, también permitía nuevos escenarios que les daban posibilidades de sobrevivir a corto plazo. Por ello, se estableció un escenario en donde las relaciones sociales se modificaban a partir de la ocupación de la tierra, gracias a las agresiones de los acaparadores de tierra.

En pocas palabras, no se trataba de una mera ocupación del territorio por parte de las haciendas, sino del establecimiento de una relación

31 Censos de 1910. AHED. Fondo: Registro Civil. Caja sin clasificar.

32 Villa Guerrero, Élites y revolución..., p. 37.

33 Panfleto de la Compañía Minera de Peñoles. Durango. Dgo. 1 de enero de 1907. AHED. Fondo: Correspondencia de Gobernadores, caja sin clasificar.

34 Convenio celebrado entre Pablo Martínez del Río y Harry Morán, representante de la Compañía The Velardeña Minig and Smelting Co. Centro de Estudios de Historia de México del Grupo CARSO (en adelante: CEHM). Fondo: DCXXIII, Caja 2. 
de mutua dependencia con la minería, la cual se convertía en su mercado natural. Las haciendas y la minería acapararon la tierra y la mano de obra, gracias a que la proximidad y el auge de los centros mineros alteraba la dinámica de las haciendas y comunidades, al buscar siempre su expansión, sin importarle si se trataba de tierras ricas para el cultivo. ${ }^{35}$

\section{EXPLOTACIÓN DEL GUAYULE}

Otro factor que contribuyó a la importancia económica de la región fue la producción de guayule, la cual, al ayudar a satisfacer la demanda de caucho para la industria automovilística en Estados Unidos, se convirtió en uno de los negocios más rentables en la entidad, tanto por la poca necesidad de agua para su mantenimiento, como por los altos precios en el mercado mundial durante el cambio de siglo. Según cálculos de la época, en una hectárea podían sembrarse 15,000 plantas de guayule, que en seis años podrían producir 6,000 kilogramos de goma, y si tomamos en cuenta que en dicho año el precio de ésta por tonelada era de 150 pesos o 15 centavos por kilo, podría generar una ganancia de 900 pesos en seis años o 150 pesos por año. Este negocio se muestra más redituable si se compara con el resto de los cultivos, en donde, por ejemplo, con la cantidad de agua que se utilizaba para mantener una hectárea de algodón por un año, podía mantenerse una superficie cuatro o cinco veces mayor sembrada con guayule. Y ya que este cultivo fue el que más rápidamente recuperó su alto precio después de la crisis de 1907-1908, era mucho más provechoso dedicarse al cultivo de guayule que al de cultivos fundamentales para la subsistencia de la población, como maíz o frijol. ${ }^{36}$

Por tal razón, los latifundistas de Cuencamé buscaron adueñarse de los terrenos donde crecía el guayule para obtener el monopolio de la producción y comercialización de dicha planta. Para 1910, Cuencamé se había convertido en el partido con más alta generación

35 Minuta de la descripción del terreno que necesita el ferrocarril de la Velardeña para su derecho de vía. CEHM. Fondo: DCXXIII, Caja 2.

36 "Algunos datos sobre el guayule", Periódico Oficial del Gobierno del Estado de Durango, México, Durango, 27 de febrero de 1910, p. 10. 
de guayule, al aportar $50.52 \%$ de la producción estatal. ${ }^{37}$ Su explotación en la región significó la entrada masiva de capital internacional por parte de las compañías que buscaban un sustituto al caucho, cuyo precio no dejaba de aumentar debido al desarrollo de la industria automovilística en Estados Unidos y Europa. Durante la primera década del siglo XX, 12\% del capital invertido en el guayule en la región era mexicano; $11 \%$ era estadounidense; 38\% era germano-británico; y 39\% era mexicano-estadounidense..$^{38}$ En este escenario, se encontró una fuerte competencia entre los inversionistas que querían asegurar el control de la producción, ya que mientras se dio un enfrentamiento entre los inversionistas mexicanos, quienes poco a poco fueron remplazados por capital extranjero en algunos casos, también se presentó una alianza entre una parte de la estructura empresarial nacional y los inversionistas que arribaron principalmente de los Estados Unidos.

La lucha por el control del guayule no significó únicamente la llegada de las compañías extranjeras que buscaban apoderarse de las materias primas del país, sino un proceso que tenía su propia lógica interna, ya que en el oriente de Durango ya se habían establecido las condiciones de conectividad ferrocarrilera, la expansión de un centro industrial lo suficientemente cercano (la Comarca Lagunera) y la estructura de explotación agrícola legal, como para asegurar su expansión en perjuicio de las comunidades. ${ }^{39}$

\section{CONFLICTOS AGRARIOS}

Cuencamé fue un territorio con profundas trasformaciones, ya que presentó la yuxtaposición de diversos procesos que se retroalimen-

37 Memoria presentada al $\mathrm{H}$. Congreso del Estado por el gobierno del mismo, sobre los actos de administración pública durante el periodo del 16 de septiembre de 1908 al 16 de septiembre de 1910, Durango, Imprenta de la Mariposa, 1910, Anexo 82. AHED. Fondo Secretaría de Gobierno siglo XX.

38 Villa Guerrero, Guadalupe, "Riqueza en suelo eriazo. La industria guayulera y los conflictos interregionales de la elite norteña en México", Secuencia: revista de historia y ciencias sociales, Instituto de Investigación Dr. José María Luis Mora, México, D.F., núm. 46, enero-abril de 2000, pp. 93-120.

39 Cerutti, Mario, "Actividad económica y grupos empresariales en el norte de México a comienzos del siglo Xx. El eje Chihuahua/La Laguna/Monterrey", en Rojas, Beatriz (coord.), El poder y el dinero. Grupos y regiones mexicanas en el siglo XIX, México, Instituto de Investigación Dr. José María Luis Mora, 1994, pp. 330-363. 
taron y condicionaron para establecer una estructura de relaciones a través de la explotación de los recursos naturales entre los diversos actores sociales. En este proceso complejo, se dio la mutua dependencia entre la trasformación de la economía política para asegurar su inserción en el mercado mundial como productor de materias primas y la dinámica interna propia de los conflictos agrarios del Partido de Cuencamé.

Si bien los conflictos entre las comunidades y los grandes latifundios no se iniciaron durante el porfiriato, ${ }^{40}$ sin duda las políticas sobre la apropiación de la tierra por parte del régimen de don Porfirio agudizaron los conflictos. A través de las leyes sobre terrenos baldíos que dejaban sin defensa legal efectiva a las comunidades, debido a que carecían de títulos primordiales, o bien, éstos eran inexactos en cuanto al señalamiento de los límites de las tierras que les correspondían, los hacendados de Durango, gracias a sus relaciones políticas y económicas, pudieron llevar a cabo una ocupación paulatina del territorio que por muchos años diversos pueblos habían considerado como propio. ${ }^{41}$

El Partido de Cuencamé se caracterizó por una larga tradición de resistencia al expansionismo de las haciendas, el cual no se expresó únicamente en la apropiación indiscriminada de tierra, sino en la formación de una estructura de dominación, como el cercamiento y el control de las fuentes de agua, que obligaba a las comunidades a mantener una fuerte dependencia respecto a la hacienda para asegurar la satisfacción de sus necesidades. ${ }^{42} \mathrm{Si}$ bien la dinámica económica generaba una participación de las haciendas y las comunidades campesinas, en donde una se volvía necesaria para el funcionamiento de la otra, esto no quiere decir que la mutua dependencia entre los actores de la sociedad haya significado un equilibrio en sus relaciones, tanto respecto a la capacidad para explotar el entorno, como en los aspectos de influencia política, ni mucho menos que todos los actores

40 Vargas-Lobsinger, María, Formación y decadencia de una fortuna: los mayorazgos de San Miguel de Aguayo y San Pedro del Álamo 1583-1823, México, Instituto de Investigaciones Históricas de la Universidad Nacional Autónoma de México, 1992.

41 Quiñones Martínez, Cynthia Teresa, "Las leyes de tierras de 1856 a 1909 y su impacto en la propiedad territorial en Durango", en Rodríguez López, Guadalupe (coord.), Historia General del Estado de Durango, Siglo XIX, Durango, Instituto de Investigaciones Históricas de la Universidad Juárez del Estado de Durango, 2013, pp. 222-272.

42 "Carta remitida de los vecinos de Sauces de Salinas", La Evolución, México, Durango, 7 de marzo de 1909, p. 3. 
estuvieran satisfechos con su papel en la estructura económica-social desarrollada en Cuencamé.

El campesino se hallaba en condiciones de gran desigualdad respecto a los terratenientes, ya que presentaba una creciente limitación cuantitativa y cualitativa en su acceso a los recursos naturales (tierra, agua, bosques), y una restricción tecnológica y económica frente a la falta de crédito y, sobre todo, a una poca capacidad de negociación. Esto generaba una dependencia de las circunstancias del mercado mucho mayor que para los hacendados. ${ }^{43}$

El caso más representativo de resistencia en Cuencamé, por su duración y relativo éxito, es el de los pueblos unidos de Santiago y San Pedro Ocuila, debido a que para 1910 eran las únicas comunidades campesinas, junto con las cabeceras municipales, cuyas tierras no habían sido ocupadas totalmente por los latifundios. ${ }^{44}$ Estos pueblos lograron resistir a pesar de su ubicación geográfica. Santiago y San Pedro Ocuila estaban rodeados por la hacienda de Atotonilco de Campa, la cual se dividió entre sus dueños en 1890: las familias López Negrete y González Saravia; por ello, surgiendo las haciendas de Atotonilco y Sombreretillos, siendo esta última la que heredó los conflictos con el pueblo de San Pedro Ocuila. ${ }^{45}$ El enfrentamiento que se originó entre estas comunidades y las estructuras latifundistas vecinas dio inicio a una fase jurídica con el denuncio presentado por Ladislao López Negrete y Buenaventura González Saravia sobre dichos pueblos en 1889. Es importante mencionar que de los denuncios de terrenos baldíos que se registraron en Cuencamé de 1867 a 1909, el de Ocuila fue el único hecho por la hacienda de Atotonilco. ${ }^{46}$

Al dividirse la hacienda entre sus dueños, la lucha se centró en la delimitación de las propiedades, debido a que mientras los dueños de Sombreretillos consideraban que los pueblo de Santiago y San Pedro Ocuila invadían su territorio constantemente ${ }^{47}$ los miembros de di-

43 Appendini, Kirsten de et al., El campesinado en México: dos perspectivas de análisis, México, El Colegio de México, 1983, p. 20.

44 Rouaix, op. cit., pp. 155-158.

45 Villa Guerrero, Élites y revolución..., pp. 29-31.

46 Quiñones Martínez, Cynthia Teresa, "Base de datos de los denuncios de terrenos baldíos, demasías y excedencias, 1867 a 1909 del Partido de Cuencamé", Manuscrito inédito, 2010. Agradezco a la Mtra. Cynthia Teresa Quiñones Martínez, doctoranda en el Colegio de Michoacán, el haberme proporcionado esta información.

47 Carta de Esteban Fernández a Porfirio Díaz. México, D.F. 21 de febrero de 1910. APD. Legajo: XXXV, Documentos: 001674-001675. 
chas comunidades denunciaban la complicidad entre los terratenientes y las autoridades políticas del partido. ${ }^{48}$ Este caso de abuso del jefe político llegó hasta la Suprema Corte de Justicia de la Nación en $1899,{ }^{49}$ pero en 1909 se les dio la razón a las autoridades locales y, por lo tanto, a los hacendados..$^{50}$

A principios de enero, de 1909, los vecinos de San Pedro Ocuila sorprendieron a un grupo de trabajadores de la hacienda de Sombreretillos realizando labores de cercamiento en tierras en disputa. Manuel Díaz, mayordomo de la hacienda, agredió a los vecinos con un arma de fuego, por lo que fue detenido y entregado al jefe político de Cuencamé. No obstante, Felipe Alemán lo dejó en libertad. Al parecer, la liberación del mayordomo de la hacienda de Sombreretillos reflejó la alianza entre las autoridades del partido y el grupo de los terratenientes.

Días después, el 20 de enero, ocurrió una emboscaba dirigida por Manuel Díaz en contra de algunos comuneros que intentaban detener nuevamente la instalación de cercas en las tierras que consideraban propias. El resultado fue dos comuneros muertos, por lo que los sobrevivientes del ataque, a los que se sumaron hombres, mujeres y niños, se dirigieron a la cabecera municipal para linchar al jefe político por haber puesto en libertad a Díaz. Sin embargo, Severino Cenicero, abogado representante de San Pedro Ocuila, logró salvar la vida del jefe político. Frente a esta situación, los comuneros se dirigieron a la hacienda de Sombreretillos, en donde al no encontrar a los agresores, se disgregó la multitud. ${ }^{51}$

A inicios de marzo del año siguiente, el juez de letras de Cuencamé se dirigió a San Pedro Ocuila para darle posesión a los dueños de la hacienda de Sombreretillos las tierras en disputa; al ser rechazado por los pobladores, regresó al día siguiente con un contingente de fuerzas rurales que tomaron el control de la comunidad, pero no

48 Carta de los vecinos de Santiago y San Pedro Ocuila a Porfirio Díaz. Cuencamé, Dgo. 2 de marzo de 1909. APD. Legajo: XXXIV, Documento: 004656.

49 Expediente de juicio de amparo promovido por los vecinos del pueblo de San Pedro Ocuila. México, D.F. 1899. Archivo Central de la Suprema Corte de Justicia de la Nación (en adelante ACsciN). Fondo: Suprema Corte de Justicia de la Nación. Acervo del siglo XIX. Exp. 1640.

50 Expediente de juicio de amparo promovido por los vecinos del pueblo de San Pedro Ocuila, México. D.F. 1909. ACscjn. Fondo: Suprema Corte de Justicia de la Nación. Acervo del siglo XIX. Exp. 1697.

51 "Los sucesos de Cuencamé", La Evolución, México, Durango, 24 de enero de 1909, p. 2.

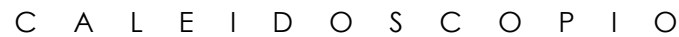


encontraron a los líderes de la resistencia, quienes, encabezados por Calixto Contreras, se habían dirigido al monte, en donde permanecerían en lucha hasta que se unieron al levantamiento convocado por Francisco I. Madero el 20 de noviembre de $1910 .^{52}$ Para ese momento, la influencia de los hacendados sobre las autoridades políticas era tan grande, que un ex administrador de la hacienda de Sombreretillos fue nombrado líder de los contingentes de fuerzas rurales en la región. ${ }^{53}$

En la primera década del siglo xx, el Partido de Cuencamé vivió la consolidación de distintos elementos que habían asegurado el control de los hacendados sobre las estructuras económicas, políticas y legales que regían la convivencia de la colectividad, como la consolidación de nuevas vías de comunicación (ferrocarril) y la consiguiente interrelación con mercados cada vez más grandes y extensos.

Los hacendados, que controlaban la región de Cuencamé, formaron una interpretación de sus relaciones con la comunidad, ya que, por un lado, los comuneros carecían de toda responsabilidad por su precaria situación económica y, por el otro, los terratenientes no veían la acumulación de tierra y el monopolio de los productos básicos como causa de las tensiones sociales, sino como consecuencia lógica del progreso de los mejores elementos de la sociedad. Es decir, al basarse en interpretaciones evolucionistas del desarrollo histórico de las colectividades, para el hacendado no había relación con el entorno más allá del establecido por las leyes del mercado, lo que a su vez garantizaba el porvenir de la nación al promover el desarrollo de sus mejores elementos. Esta situación generó una interpretación positivista de la idea de progreso material como meta de la estructura legal, política y social. ${ }^{54}$

Aquí se presenta un factor más en la compleja gama de las relaciones entre los diversos actores sociales del oriente de Durango, ya que los elementos de cambio que llegaron desde finales del siglo XIX, si bien modificaron la estructura interna de las haciendas y revitalizaron el papel de las familias de latifundistas relacionándolos con el exte-

52 Favela González, Jaime, Cuencamé, tierra de generales, México, Concejo Nacional para la Cultura y las Artes-Instituto de Cultura del Estado de Durango, 2011, p. 79.

53 Carta de Laureano López Negrete a Esteban Fernández. México, D.F. 29 de diciembre de 1910. AHED. Fondo: Correspondencia de Gobernadores. Exp. 510.

54 Córdova, Arnaldo, La ideología de la revolución mexicana. La formación del nuevo régimen, México, Ediciones Era, 1973, pp. 53-79. 
rior, también consolidaron, a partir de la ideología moderna basada en Spencer y Comte, las relaciones sociales, políticas y económicas a partir del férreo control del régimen porfirista.

Los hacendados establecieron una lógica de relación con el territorio basada en su explotación para cumplir con las demandas del mercado nacional e internacional; al contrario, las comunidades, como Santiago y San Pedro Ocuila, dirigieron sus esfuerzos para satisfacer las necesidades internas. Porque en este tipo de estructuras campesinas la vida familiar y social no tenían una frontera definida, sino que los diferentes elementos de la vida laboral se interrelacionaban con la composición y relaciones dentro del núcleo familiar, determinando una a la otra y, por lo tanto, la trasformación de la tenencia de la tierra no era un mero elemento económico, sino que generaba una alteración profunda dentro de las pequeñas comunidades. ${ }^{55}$

Al inicio del levantamiento maderista, tampoco había una separación entre la sociedad y las fuerzas armadas. Las personas que se manifestaron en el pueblo de San Pedro Ocuila en 1909, o en los otros episodios parecidos que se desarrollaron posteriormente en todo Cuencamé para defender su tierra y vengar a sus compañeros caídos, son los mismas que se dedicaban a labrar la tierra o que trabajaban en las minas; es decir, todavía no estaba presente esa peculiaridad de las fuerzas norteñas durante la revolución contra Huerta, en donde se profesionalizó militarmente a los campesinos. ${ }^{56}$ Con ello, se ve cómo la sociedad de Cuencamé se había transformado a partir del uso de la violencia para reivindicar lo que consideraban sus derechos sobre el uso de la tierra, como ejemplifica el caso de los pueblos de Santiago y San Pedro Ocuila después de la agresión de los hacendados, ya que era la primera vez que como comunidad se generaba una reacción armada en contra de la hacienda que consideraban el centro y origen de sus diversos problemas.

A partir de este episodio, en apariencia controlado por la presencia de las fuerzas rurales, se desarrollaron una serie de cambios en los habitantes de Cuencamé, los cuales, a pesar de pertenecer al bando perdedor en la lucha entre los convencionalistas y los constitucionalistas, lograron presentar una defensa eficaz para lograr evitar que las

55 Chayanov, Alexander, La organización de la unidad económica campesina, Buenos Aires, Nueva Visión, 1925

56 Wolf, Eric, Las luchas campesinas del siglo XX, México, Siglo XXI, 1969, pp. 54-59.

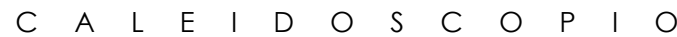


antiguas posesiones y el poder político y económico fueran recuperadas por los hacendados en los años veinte.$^{57}$ El levantamiento popular en San Pedro Ocuila fue el punto de inflexión en que se pasa de la confrontación legal y política al establecimiento de una estrategia militar de defensa de la tierra de las comunidades, la cual, al insertarse en los acontecimientos nacionales, ya no sería abandonada por los habitantes de Cuencamé.

Al analizar en retrospectiva la trasformación de Cuencamé en la llamada "fábrica de generales", ${ }^{58}$ ésta tiene un punto trascendental en el episodio de San Pedro Ocuila, el cual, a la vez que es prueba de las relaciones entre los grupos de poder, también refleja la cohesión social que la pequeña comunidad adquirió a través de la lucha constante con las estructuras que buscaban monopolizar la tierra desde la época de la colonia. El calificarse a sí mismos como "indios ocuilas" en sus propios documentos, ${ }^{59}$ a pesar de que en los censos de 1900 y 1910 no hay ningún hablante de lengua indígena en Cuencamé, cuyos pobladores, desde un punto de vista estricto, eran mestizos, hace inferir que su cohesión social fue resultado de las luchas por la tierra, libradas desde la época virreinal y no por elementos raciales o lingüísticos.

El paréntesis de pacificación relativa que significó la presidencia de Madero en el país no desmanteló la estructura organizativa de la sociedad de Cuencamé y, particularmente, de los pueblos de Santiago y San Pedro Ocuila, sino que permitió un reacomodo de fuerzas entre las haciendas y las comunidades, que, a través de la lucha armada, se había formado. Gracias a ello, los dueños de la hacienda de Sombreretillos entablaron negociaciones con el gobierno para que éste les comprara tierras que podría repartir entre los pobladores de los pueblos de Ocuila, pidiendo 600,000 pesos por ellas y el derecho al guayule que permaneciera en sus confines o 1,200,000 pesos si no se

57 Walker, David, "Sueños desencantados: la reforma agraria y el corporativismo en el Durango posrevolucionario, México 1920-1930", en Cano Cooley, Gloria y Mario Cerutti (coords.), Porfiriato y revolución en Durango, Durango, Instituto de Investigaciones Históricas de la Universidad Juárez del Estado de Durango, 1992, pp. 225-279.

58 Durante la Revolución mexicana, 17 de los militares con este rango que lucharon en la División del Norte eran originarios de esta región del oriente de Durango. Véase Vargas Arreola, Juan Bautista, A sangre y fuego con Pancho Villa, México, Fondo de Cultura Económica, 1988, pp. 324.

59 Carta de los vecinos de Santiago y San Pedro Ocuila a Porfirio Díaz. Cuencamé, Dgo. 25 de enero de 1909. APD. Legajo: XXXII. Documento: 012913. 
les entregaba el derecho sobre dicha planta. Ambas propuestas fueron consideradas excesivas. ${ }^{60}$

Finalmente, el gobierno y la familia López Negrete acordaron la entrega de 20 sitios de terreno de ganado menor para la comunidad, lo cual sólo era legalizar un hecho ya consumado, debido a que los campesinos de los pueblos de Ocuila habían ocupado la tierra que consideraban como propia a partir del triunfo maderista. ${ }^{61}$ Desde el fin del régimen de Díaz, los revolucionarios de Ocuila practicaron el robo y saqueo de la hacienda de Sombreretillos por calificar a sus dueños como enemigos de la revolución triunfante y, por lo tanto, considerar que sus bienes debían ser ocupados por las fuerzas insurrectas. ${ }^{62}$

Los pobladores de Santiago y San Pedro Ocuila, dirigidos por Calixto Contreras, tuvieron un importante desempeño en contra del levantamiento de Pascual Orozco y dentro de la División del Norte en la lucha contra Huerta y Carranza. Sin embargo, a finales de 1915, Cuencamé fue ocupado por el ejército de Venustiano Carranza, el cual bombardeó las comunidades para reducir la resistencia. Posteriormente, se prosiguió con la expulsión de sus pobladores hacia la ciudad de Durango. ${ }^{63}$

La lucha armada permitió que las comunidades de Ocuila, y de todo Cuencamé, hicieran lo que el régimen porfirista sólo había pensado para la estructura económica y los hombres de negocios: establecer y aprovechar la conectividad con las zonas circunvecinas y los territorios muy alejados, pero no desde el punto de vista de la explotación de materias primas para las potencias extranjeras, sino a través de la redefinición de las relaciones sociales con los elementos de poder al equipararse con ellos, como al momento de reemplazar a los hacendados en la venta de guayule por las compañías extranjeras. ${ }^{64}$ Gracias a su inserción en la lucha estrictamente militar, la cual no sería abandonada totalmente en muchos años, la sociedad de los pueblos de Ocuila se trasformó definitivamente. Con las presiones po-

60 "Los terrenos de Ocuila", La Evolución, México, Durango, 25 de junio de 1911, p. 2.

61 "Lo de Ocuila", El Monitor, México, Durango, 11 de febrero de 1912, p. 2.

62 "Robo de mulas a la hacienda de Sombreretillos", El Criterio, México, Durango, 15 de octubre de 1911, p. 3.

63 Favela González, op. cit., pp. 77-156

64 Carta de López Negrete Hermanos a Luis Alonso Gala, Durango, Dgo. 1 de febrero de 1912. AHED. Fondo: Correspondencia de Revolución. Exp. 153. 
líticas y el uso del derecho a la lucha armada, se generó un empoderamiento de las comunidades frente a las estructuras de las haciendas, las cuales eran símbolo y síntesis de las dificultades que, a su vez, fomentaban la cohesión de Santiago y San Pedro Ocuila.

Por ello, es importante reflexionar sobre el papel de la insurrección de los pueblos de Ocuila como el suceso que permitió a los habitantes de dicho poblado estar preparados para su entrada en la lucha nacional y, a su vez, conectar sus reivindicaciones locales con la formación de movimientos de mayor alcance. A través de reconocer la utilización de la violencia como la única vía disponible para asegurar una pronta solución a las disputas con las haciendas, se trasformó la manera de entender la resolución de los conflictos y su capacidad para lograrlo, debido a que a pesar de haber llevado a cabo largos procesos legales para asegurar la protección de lo que consideraban sus derechos sobre la tierra, después de ocuparla gracias al uso de las armas, no parecieron mostrar demasiado interés en reglamentar dicha posesión mediante el derecho, por lo menos no a corto y mediano plazo.

La Revolución mexicana permitió que las comunidades de Ocuila revalorizaran su interpretación de las relaciones sociales, debido a que durante el porfiriato habían permanecido a la defensiva por el cercamiento de la tierra y un jefe político complaciente con los poderes de las haciendas. De esta manera, las relaciones sociales cambiaron radicalmente en Santiago y San Pedro Ocuila, ya que sus habitantes lograron construir una conciencia propia para resolver sus problemas, establecer relaciones de cooperación con otros movimientos semejantes y debilitar los latifundios.

FUENTES CONSULTADAS

\section{Archivos}

Archivo Central de la Suprema Corte de Justicia de la Nación (ACSCJN). Archivo Histórico del Estado de Durango (AHED).

Archivo Porfirio Díaz de la Universidad Iberoamericana (APD).

Centro de Estudios de Historia de México del Grupo CARSO (CEHM). 


\section{Hemerografía}

El Criterio (Durango), 1911.

El Monitor (Durango), 1912.

La Evolución (Durango), 1909, 1911.

Periódico Oficial del Gobierno del Estado de Durango (Durango), 1902, 1905, 1910.

\section{Bibliografía}

Appendini, Kirsten de, Marielle Pepin-Lehalleur, Teresa Rendón y Vania A. de Salles, El campesinado en México: dos perspectivas de análisis, México, El Colegio de México, 1983.

Arreola Valenzuela, Antonio, Durango, más de un siglo sobre rieles, Durango, Instituto de Investigaciones Históricas de la Universidad Juárez del Estado de Durango, 1992.

Cano Cooley, Gloria, "Tenencia de la tierra en el Estado de Durango según los padrones catastrales de 1898", Tesis de maestría, Instituto de Investigaciones Históricas de la Universidad Juárez del Estado de Durango, 2013.

Cerutti, Mario, "Actividad económica y grupos empresariales en el norte de México a comienzos del siglo xx. El eje Chihuahua/La Laguna/ Monterrey", en Rojas, Beatriz (coord.), El poder y el dinero. Grupos y regiones mexicanas en el siglo XIX, México, Instituto de Investigación Dr. José María Luis Mora, 1994.

Chayanov, Alexander, La organización de la unidad económica campesina, Buenos Aires, Nueva Visión, 1925.

Córdova, Arnaldo, La ideología de la revolución mexicana. La formación del nuevo régimen, México, Ediciones Era, 1973.

Favela González, Jaime, Cuencamé, tierra de generales, México, Concejo Nacional para la Cultura y las Artes-Instituto de Cultura del Estado de Durango, 2011.

Fernández de Castro, Patricia, "El Porfiriato visto a través de los censos de población", en Rodríguez López, Guadalupe (coord.), Historia General del Estado de Durango, tomo III, Siglo XIX, Durango, Instituto de Investigaciones Históricas de la Universidad Juárez del Estado de Durango, 2013.

Katz, Friedrich, Pancho Villa, México, Era, 1998. 
Martínez Guzmán, Gabino y Juan Ángel Chávez Ramírez, Durango: un volcán en erupción, México, Fondo de Cultura Económica, 1998.

Quiñones Martínez, Cynthia Teresa, "Base de datos de los denuncios de terrenos baldíos, demasías y excedencias, 1867 a 1909 del Partido de Cuencamé", Manuscrito inédito, 2010.

"Las leyes de tierras de 1856 a 1909 y su impacto en la propiedad territorial en Durango", en Rodríguez López, Guadalupe (coord.), Historia General del Estado de Durango, tomo III, Siglo XIX, Durango, Instituto de Investigaciones Históricas de la Universidad Juárez del Estado de Durango, 2013.

Rouaix, Pastor, Geografía del Estado de Durango, México, Secretaría de Agricultura y Fomento, 1929.

Salmerón, Pedro, La División del Norte: la tierra, los hombres y la historia de un ejército del pueblo, México, Planeta, 2006.

Juárez, la rebelión interminable, México, Planeta, 2007.

Vargas Arreola, Juan Bautista, A sangre y fuego con Pancho Villa, México, Fondo de Cultura Económica, 1988.

Vargas-Lobsinger, María, Formación y decadencia de una fortuna: los mayorazgos de San Miguel de Aguayo y San Pedro del Álamo 1583-1823, México, Instituto de Investigaciones Históricas de la Universidad Nacional Autónoma de México, 1992.

Villa Guerrero, Guadalupe, "La minería en la era de la paz y del trabajo", en Cano Cooley, Gloria y Mario Cerutti (coords.), Porfiriato y revolución en Durango, Durango, Instituto de Investigaciones Históricas de la Universidad Juárez del Estado de Durango, 1992.

"Durango en la era de la paz y del progreso", en Altamirano, Graziella et al. (coords.), Durango, una historia compartida 1821-1920, México, Instituto de Investigación Dr. José María Luis Mora, 1997, pp. 234-324.

"Riqueza en suelo eriazo. La industria guayulera y los conflictos interregionales de la elite norteña en México", Secuencia: revista de historia y ciencias sociales, Instituto de Investigación Dr. José María Luis Mora, México, D.F., núm. 46, enero-abril de 2000, pp. 93-120.

Élites y revolución en Durango, México, Instituto de Investigación Dr. José María Luis Mora, 2010.

Walker, David, "Sueños desencantados: la reforma agraria y el corporativismo en el Durango posrevolucionario, México 1920-1930", en Cano Cooley, Gloria y Mario Cerutti (coords.), Porfiriato y revolución 
en Durango, Durango, Instituto de Investigaciones Históricas de la Universidad Juárez del Estado de Durango, 1992, pp. 225-279. , "Continuidad y cambio en Cuencamé, Durango 1895-1930",

Ponencia presentada en el Congreso Anual del Departamento de Estudios Latinoamericanos de las Rocallosas, Colorado, 18-20 de febrero de 1999.

Wolf, Eric, Las luchas campesinas del siglo XX, México, Siglo XXI, 1969. 
